\title{
Immunohistochemical heterogeneity of breast carcinomas negative for estrogen receptors, progesterone receptors and Her2/neu (basal-like breast carcinomas)
}

\author{
Enrique Lerma ${ }^{1}$, Gloria Peiro ${ }^{2}$, Teresa Ramón ${ }^{3}$, Sonia Fernandez ${ }^{1}$, Daniel Martinez ${ }^{1}$, \\ Cristina Pons ${ }^{1}$, Fina Muñoz ${ }^{1}$, Josep $\mathrm{M}^{\mathrm{a}}$ Sabate $^{4}$, Carmen Alonso ${ }^{3}$, Belén Ojeda ${ }^{3}$, \\ Jaime Prat ${ }^{1}$ and Agustí Barnadas ${ }^{3}$
}

${ }^{1}$ Department of Pathology, Hospital de la Santa Creu i Sant Pau, Barcelona, Spain; ${ }^{2}$ Department of Pathology, Hospital General, Alicante, Spain; ${ }^{3}$ Department of Oncology, Hospital de la Santa Creu i Sant Pau, Barcelona, Spain and ${ }^{4}$ Department of Radiology, Hospital de la Santa Creu i Sant Pau, Barcelona, Spain

\begin{abstract}
Basal breast carcinomas triple negative for estrogen receptors, progesterone receptors and Her2/neu breast carcinomas are more aggressive than conventional neoplasms. We studied 64 cases with immunohistochemistry, using 23 antibodies, to characterize diverse pathological pathways. A basal cytokeratin was identified in $81 \%$ of tumors and vimentin was identified in $55 \%$. The mean Ki67 index was $46 \%$ (range, 10-90\%). Coincident expression of $\mathrm{p} 50$ and p65, which suggests an active nuclear factor- $\mathrm{B}$ factor, was present in $13 \%$ of neoplasms. Epithelial growth factor receptor (EGFR), insulin-like growth factor-I receptor (IGF-IR) or c-kit (CD117) was identified in $77 \%$ of tumors. Loss of protein tyrosine phosphatase was found in $14 \%$, whereas Akt activation was present in $\mathbf{2 8} \%$. Several differences were identified between two subtypes of basal breast carcinomas: the pure variant (negative S-100 and actin) was more frequently associated with 'in situ carcinoma' $(P=0.019)$ and pBad overexpression $(P=0.098)$, whereas the myoepithelial variant (positive $S-100$ or actin) showed more frequent tumor necrosis $(P=0.048)$, vimentin expression $(P=0.0001)$, CD117 expression $(P=0.001)$ and activated caspase-3 $(P=0.089)$. IGF-IR could be as important as EGFR for the growth of these neoplasms. Basal cell carcinoma has at least two subtypes with distinct microscopic and immunohistochemical features.
\end{abstract}

Modern Pathology (2007) 20, 1200-1207; doi:10.1038/modpathol.3800961; published online 21 September 2007

Keywords: breast; carcinoma; immunohistochemistry; growth membrane receptors; IG-FR; PTEN; Akt

Breast cancer is one of the most frequent malignancies in women and ranks second among cancer deaths in adult females. ${ }^{1}$ At diagnosis, approximately $70-80 \%$ of breast carcinoma are positive for estrogen receptors (ERs) and/or progesterone receptors (PgRs), and $\sim 20 \%$ overexpress Her-2/neu. ${ }^{2-4}$ These findings could be related with gene expression-profiling studies, ${ }^{5-14}$ which identify diverse varieties of breast carcinoma, mainly the 'luminal' one associated with hormone receptors, the 'Her-2/ neu-positive' and the 'basal' or 'triple negative'

Correspondence: E Lerma, MD, Department of Pathology, Hospital Santa Creu i Sant Pau, Avda. Sant Antonio Ma Claret, 167, Barcelona 08025, Spain.

E-mail: elerma@santpau.es

Received 3 April 2007; revised and accepted 10 August 2007; published online 21 September 2007 breast carcinoma (negative for ERs, PgRs and Her2/neu).

Basal breast carcinoma includes $15-25 \%$ of breast cancers, and it has been correlated with aggressive behavior, poor prognosis and better response to chemotherapy than conventional breast carcinoma. This variety of breast carcinoma was characterized by genetic studies and by immunohistochemical expression of basal cytokeratins, mainly types 5, 14 and 17, epidermal growth factor receptor (EGFR) and p53, ${ }^{15-30}$ but results from diverse studies are not always concordant. Recently, 'pure' and 'myoepithelial' variants of basal breast carcinoma were described, based on S-100, actin or p63 expression. Although these subtypes share some concordances in gene profiles and cytokeratin expressions, only the pure variant was associated with shorter survival in the multivariate analyses. ${ }^{17}$ Based on the above-reported heterogeneity of basal breast carci- 
nomas, further studies seem necessary to better describe the characteristics of this neoplasm, which in turn may improve the knowledge of its growth and dissemination pathways. In this study, we analyze the role and relationship of several factors related with the cell cycle (Ki67, p53, p27, cyclin D1, p50, p52 and p65), membrane growth factor receptors other than Her2 (EGFR, insulin-like growth factor-I receptor (IGF-IR), platelet-derived growth factor receptor- $\alpha$ (PDGFR $\alpha$ ) and CD117) and proteins involved in the phosphoinositide-3 kinase (PI3K)/protein tyrosine phosphatase (PTEN)/Akt signaling pathway (PTEN, Akt, and Bad and caspase3 ) in a series of basal breast carcinomas.

\section{Materials and methods}

Sixty-four breast carcinomas that were triple negative for ERs, PgRs and Her-2/neu were diagnosed between 2000 and 2006. All hematoxylin- and eosinstained sections of these tumors were reviewed to confirm conventional morphological parameters. Histological grades were assigned using modified Elston \& Ellis criteria. ${ }^{31}$ Three representative areas of each tumor were then selected to build three tissue microarrays. Serial, $5-\mu$ m- thick tissue sections were used for immunohistochemical staining with the Envision method (Dako). Antibodies, dilutions, antigen retrieval methods and suppliers are listed in Table 1. Then, we studied the expression of S-100 and smooth muscle actin (SMA) to identify myo- epithelial differentiation, basal cytokeratins (types 5/6, 14, 17), luminal cytokeratins (types 8/18) and vimentin. Ki67, p53, p27 and cyclin D1 were studied among the cell cycle-related proteins. Analyses of the nuclear factor- $\kappa \mathrm{B}(\mathrm{NF}-\kappa \mathrm{B})$ pathway included the study of p50, p52, p65 and IKK $\alpha$. In addition, diverse membrane receptors other than Her-2 were studied: Her-1(EGFR), platelet-derived growth factor receptor- $\alpha$ (PDGFR $\alpha$ ), IGF-IR and c-kit (CD117). Investigation of the PI3K/PTEN/Akt pathway included the analysis of PTEN, phosphorylated Akt (pAkt), phosphorylated Bad (pBad) and activated caspase-3 expression.

Two pathologists (EL and SF) evaluated the immunohistochemical stainings blinded to patient outcome. Discordances were reviewed to achieve agreement.

The percentage of stained nuclei was evaluated, independent of the intensity, for Ki67, p53, p27, cyclin D1 and p50, p52 and p65. The percentage of cells with cytoplasmic staining was determined for S-100, actin, CKs 5/6, 14, 17 and 8/18, and vimentin. Distinct membrane staining in $>10 \%$ of tumor cells for EGFR, IGF-IR and CD117 was counted as positive for expression. PDGFR $\alpha$ was positive when at least $10 \%$ of tumor cells showed cytoplasmic and/or membrane stainings. Immunostaining cytoplasmic scores for PTEN, pAkt and pBad were calculated by multiplying the percentage of labeled cells by the intensity of the staining (range 0-300). Scores $>150$ were considered positive. Cytoplasmic active caspase-3 was rarely detected and was always in less

Table 1 Immunohistochemistry

\begin{tabular}{|c|c|c|c|c|}
\hline Antibody & Clone & Dilution & Antigen retrieval & Supplier \\
\hline ER & $6 F 11$ & 1.40 & 1 & Novocastra \\
\hline PgR & 16 & 1200 & 1 & Novocastra \\
\hline HER-2 & Polyclonal & 1100 & 1 & Dako \\
\hline S-100 & Polyclonal & 13000 & 4 & Dako \\
\hline$\alpha$-Actin & $1 \mathrm{~A} 4$ & 1100 & 1 & Dako \\
\hline Ki67 & MIB-1 & 1.1 & 1 & Dako \\
\hline p53 & ВР53-12-1 & 1150 & 1 & BioGenex \\
\hline Cyclin D1 & SP4 & 1.50 & 3 & Neo Markers \\
\hline p27 & SX53G8 & $1: 50$ & 3 & Dako \\
\hline Cytokeratin 5/6 & D5/16B4 & $1: 50$ & 3 & Dako \\
\hline Cytokeratin 17 & E3 & 1.2 & 3 & Dako \\
\hline Cytokeratin 14 & LL002 & 1.5 & 3 & Master Diagnostic \\
\hline CAM 5.2 & CAM 5.2 & 1.1 & 4 & Becton Dickinson \\
\hline EGFR & 2-18C9 & 1.1 & 5 & Dako \\
\hline PGFR- $\alpha$ & Polyclonal & 1.1 & 3 & Cell Signaling \\
\hline IGF-IR & Polyclonal & 1.1 & 3 & Cell Signaling \\
\hline C-kit (CD117) & Polyclonal & $1: 50$ & None & Dako \\
\hline PTEN & $6 \mathrm{H} 2.1$ & $1: 50$ & 2 & Cascade Biosciences \\
\hline AKT (p) & Polyclonal & 1.20 & 3 & Cell Signaling \\
\hline NFKB p50 & Polyclonal & $1: 50$ & 3 & Santa Cruz \\
\hline $\mathrm{NF}-\kappa \mathrm{B}$ p52 & $\mathrm{C}-5$ & $1: 30$ & 3 & Santa Cruz \\
\hline NF- $\kappa \mathrm{B}$ p65 & Polyclonal & 1200 & 3 & Santa Cruz \\
\hline IKK- $\alpha$ & Polyclonal & $1: 50$ & 3 & Santa Cruz \\
\hline Active caspase-3 & Polyclonal & $1: 20$ & - & Cell Signaling \\
\hline Vimentin & V9 & 1300 & 1 & Dako \\
\hline
\end{tabular}

${ }^{\mathrm{a}}(1)$ Citrate buffer $\mathrm{pH}$ 6. Autoclave, $8 \mathrm{~min}$; (2) citrate buffer $\mathrm{pH}$ 6. Waterbath $95^{\circ} \mathrm{C}, 30 \mathrm{~min}$; (3) EDTA buffer pH 8. Autoclave, 8 min; (4) pepsin 0.1\%, $30 \mathrm{~min}$; and (5) proteinase $\mathrm{K} 0.1 \%, 5 \mathrm{~min}$. 
than $5 \%$ of cells, and the cutoff was established at $2 \%$.

Clinical followup was reviewed by one of the authors (TR). Mean followup was 21 months (range, 3-70 months), but overall survival and disease-free survival were not conclusive due to the good initial response to treatment and short followup. Finally, the pathological and immunohistochemical findings were related with clinical data and outcome.

Statistical analyses were performed with the SPSS version-4 statistical software package. Continuous and ordinal variables between the two groups were compared using the Student's $t$-test. Dichotomous variables were compared with the Fisher exact test. The Kaplan-Meier method was used to estimate survival and the log-rank test was performed to assess survival differences between groups. A twosided $P$-value of 0.05 was considered significant.

\section{Results}

The mean age of the 64 patients was 53 years (range, 25-86 years). Five patients had a history of familial breast carcinoma, and a BRCA1 mutation was detected in another case. Two patients had a previous history of breast cancer, which could not be reviewed.
The most frequent location of tumors was the upper-external quadrant of the breast $(36 \%)$ as detailed in Table 2. Thirty-eight patients (59\%) underwent a tumorectomy and $26(41 \%)$ a modified radical mastectomy. Sentinel lymph node dissection was studied in 17 cases and was positive in 7 . Dissection of axillary lymph nodes at levels I and II was performed in 33 patients with a mean of 18 nodes per patient (median: 15; range 5-45), and metastases were identified in 18 (55\%) cases.

The pathological stage at diagnosis and followup was determined in 58 patients: 21 cases were in stage I (36\%), 13 in IIA (22\%), 14 in IIB (24\%), 4 in IIIA $(7 \%), 3$ in IIIB (5\%) and 3 in IV (5\%).

Most carcinomas were between 2 and $5 \mathrm{~cm} \mathrm{(58 \% )}$ and most were of the ductal type (NOS), although 2 were medullary carcinomas, 14 atypical medullary carcinomas and 1 had extensive papillar features (2\%). A ductal 'in situ' (DCIS) component $>10 \%$ was present in $36 \%$ of tumors and $>25 \%$ in $6 \%$. Histological grading was II in $25 \%$ of tumors and III in $75 \%$. Other microscopic features are detailed in Table 2.

Immunohistochemical data are shown in Table 3 and Figure 1. Briefly, S-100 was positive in $14(22 \%)$ cases and SMA was positive in $5(8 \%)$, but 2 cases co-expressed both Ab. Therefore, $17(27 \%)$ of our basal breast carcinomas had myoepithelial differ-

Table 2 Clinicopathological findings

\begin{tabular}{|c|c|c|c|c|c|}
\hline & & Total (\%) & $P B B C(\%)$ & $M B B C(\%)$ & Statistics \\
\hline \multirow[t]{6}{*}{ Location (quadrant) } & Inferio-external & 6 & 9 & 0 & NS \\
\hline & Upper-internal & 3 & 4 & 0 & NS \\
\hline & Inferio-internal & 3 & 2 & 6 & NS \\
\hline & Upper-external & 36 & 36 & 35 & NS \\
\hline & Central & 25 & 23 & 41 & NS \\
\hline & Unknown & 27 & 26 & 18 & NS \\
\hline \multirow[t]{3}{*}{ Size } & $<2 \mathrm{~cm}$ & 37 & 43 & 24 & NS \\
\hline & $2-5 \mathrm{~cm}$ & 58 & 55 & 65 & NS \\
\hline & $>5 \mathrm{~cm}$ & 5 & 2 & 12 & NS \\
\hline \multirow[t]{6}{*}{ Stage } & I & 36 & 46 & 12 & NS \\
\hline & IIA & 22 & 20 & 29 & NS \\
\hline & IIB & 24 & 20 & 35 & NS \\
\hline & IIIA & 7 & 5 & 12 & NS \\
\hline & IIIB & 5 & 5 & 6 & NS \\
\hline & IV & 5 & 5 & 6 & NS \\
\hline \multirow[t]{2}{*}{ Ductal in situ carcinoma } & $>10 \%$ & 36 & 45 & 12 & $P=0.019$ \\
\hline & $>25 \%$ & 6 & 6 & 6 & NS \\
\hline \multirow[t]{3}{*}{ Histological grade } & I & 0 & 0 & 0 & NS \\
\hline & II & 25 & 30 & 12 & NS \\
\hline & III & 75 & 70 & 88 & NS \\
\hline \multirow[t]{3}{*}{ Nuclear grade } & 1 & 2 & 0 & 6 & NS \\
\hline & 2 & 11 & 15 & 0 & NS \\
\hline & 3 & 86 & 85 & 94 & NS \\
\hline \multirow[t]{3}{*}{ Duct formation } & 1 & 1 & 0 & 6 & NS \\
\hline & 2 & 9 & 11 & 6 & NS \\
\hline & 3 & 90 & 89 & 88 & NS \\
\hline \multirow[t]{3}{*}{ Mitoses per $0.0625 \mathrm{~mm}^{2}$} & 1 & 16 & 19 & 6 & NS \\
\hline & 2 & 34 & 36 & 30 & NS \\
\hline & 3 & 50 & 45 & 65 & NS \\
\hline Necrosis & $>10 \%$ & 55 & 47 & 76 & $P=0.048$ \\
\hline Lymphoid reaction & Present & 45 & 40 & 59 & $P=0.1$ \\
\hline Vascular invasion & Present & 20 & 15 & 35 & NS \\
\hline
\end{tabular}

NS, nonsignificant. 
Table 3 Immunohistochemical findings

\begin{tabular}{|c|c|c|c|c|}
\hline Primary antibody & $\begin{array}{c}\text { Total } \\
(\%)\end{array}$ & $\begin{array}{c}P B B C \\
(\%)\end{array}$ & $\begin{array}{c}M B B C \\
(\%)\end{array}$ & Statistics \\
\hline$S-100$ & 22 & 0 & 82 & Not done \\
\hline Actin & 8 & 0 & 29 & Not done \\
\hline Cytokeratin 5/6 & 50 & 47 & 59 & NS \\
\hline Cytokeratin 14 & 56 & 53 & 65 & NS \\
\hline Cytokeratin 17 & 58 & 53 & 65 & NS \\
\hline Cytokeratin CAM 5.2 & 80 & 81 & 76 & NS \\
\hline $\begin{array}{l}\text { Vimentin expression } \\
\text { (total) }\end{array}$ & 55 & 40 & 94 & $P=0.0001$ \\
\hline Vimentin $5-50 \%$ of cells & 19 & 21 & 12 & NS \\
\hline$>50 \%$ of cells & 36 & 19 & 82 & $P=0.0001$ \\
\hline Ki $67<20 \%$ & 20 & 21 & 18 & NS \\
\hline $20-50 \%$ & 37 & 36 & 41 & NS \\
\hline$>50 \%$ & 42 & 43 & 41 & NS \\
\hline p53 > 10\% nuclei & 53 & 51 & 59 & NS \\
\hline Cyclin D1 overexpresion & 51 & 55 & 41 & NS \\
\hline Cyclin D1 in 11-30\% & 28 & 32 & 18 & NS \\
\hline Cyclin D1 in $30-100 \%$ & 23 & 23 & 23 & NS \\
\hline Lack p27 > 50\% (total) & 56 & 53 & 65 & NS \\
\hline Lack p $27>70 \%$ & 31 & 32 & 29 & NS \\
\hline Lack p27 50-70\% & 25 & 21 & 35 & NS \\
\hline p50 & 19 & 17 & 24 & NS \\
\hline p52 & 14 & 9 & 29 & NS \\
\hline p65 & 13 & 13 & 12 & NS \\
\hline $\mathrm{IKK} \alpha$ & 100 & 100 & 100 & NS \\
\hline EGFR & 34 & 33 & 35 & NS \\
\hline PGFR- $\alpha$ & 31 & 32 & 29 & NS \\
\hline IGF-IR & 36 & 30 & 53 & NS \\
\hline C-kit & 11 & 2 & 35 & $P=0.001$ \\
\hline PTEN (score > 150) & 86 & 89 & 76 & NS \\
\hline p-Akt (score > 150) & 28 & 28 & 29 & NS \\
\hline pBad (score > 150) & 14 & 19 & 0 & $P=0.098$ \\
\hline Caspase $3>2 \%$ & 58 & 51 & 76 & $P=0.089$ \\
\hline
\end{tabular}

NS, nonsignificant.

entiation and were considered of the myoepithelial subtype.

Expressions of CK 5/6, 14, 17 and 8/18 were identified in 50, 56, 58 and $80 \%$ of tumors, respectively. Fifty-two (81\%) tumors presented one of the basal cytokeratins studied (types 5/6, 14, 17). Expression of cytokeratins $5 / 6$ was often associated with cytokeratin $17(P=0.002)$ but not with cytokeratin 14 . Vimentin was positive in $55 \%$ of tumors.

The mean percentage of Ki67-positive nuclei was $46 \%$ (median of 35 and range $10-90 \%$ ) and only $20 \%$ of tumors had a Ki67 $<20 \%$. Aberrant p53 expression ( $>10 \%$ of nuclei) was present in $53 \%$ of cases, cyclin D1 overexpression ( $>10 \%$ nuclei) was detected in $51 \%$ of tumors and loss of p27 was identified in $56 \%$. Nuclear positivity for p50, p52 and p65 was detected in 19, 14 and $13 \%$, respectively. Eight $(13 \%)$ cases had coincident p50 and p65 expressions, suggesting activation of this NF- $\kappa \mathrm{B}$ heterodimer.

Several membrane receptors were also studied: EGFR was identified in $34 \%$ of tumors, PDGFR $\alpha$ in $31 \%$, IGF-IR in $36 \%$ and CD117 in $11 \%$. Overlapping in the staining of IGF-IR, EGFR and CD117 was very rare $(P=0.078)$, except in one myoepithelial basal breast carcinoma, which stained for EGFR and CD117. Overexpression of at least one of these three membrane receptors was associated with tumor growth in $44(77 \%)$ cases. No relationship was found between PDGFR $\alpha$ and the other growth factor receptors.

Loss of PTEN expression (score < 150) was seen in $14 \%$ of tumors, whereas pAkt was positive in $28 \%$ and pBad in $14 \%$. Activated caspase- 3 was detected in $58 \%$ and was associated with the presence of pBad $(P=0.04)$.

Some correlation was detected between the expressions of IGF-IR, pAkt and pBad, although this was not statistically significant. Interestingly, loss of p27 appeared only in tumors lacking IGF-IR $(P=0.062)$.

No significant differences were detected between pure and myoepithelial variants of basal breast carcinomas in most clinicopathological features or in the immunohistochemical studies, with the exception that pure basal breast carcinomas were more frequently associated with DCIS (45 vs $12 \%$; $P=0.019$ ) and pBad overexpression (19 vs $0 \%$; $P=0.098$ ), and myoepithelial basal breast tumors more frequently showed necrosis in $>10 \%$ of the tumor cells (76 vs $47 \%$; $P=0.048$ ), marked inflammatory reaction (59 vs $40 \%, P=0.19$ ), expression of vimentin ( $>50 \%$ tumor cells) (82 VS 19\%; $P=0.0001)$, CD117 (35 vs $2 \% ; P=0.001)$ and activated caspase-3 (76 vs $51 \%$; $P=0.089$ ).

Two patients died from tumor progression: one 4 months after diagnosis of a stage IV pure variant and the second at 15 months after diagnosis of a stage IV myoepithelial variant. Five patients are presently alive with disease, three with pure variants (followup of 32, 30 and 27 months) and two with myoepithelial variants (followup of 27 and 38 months). Another patient died of other causes.

Disease-free survival was calculated according to the main characteristics. No differences were observed between the two groups and survival curves lacked significance due to the low mortality.

\section{Discussion}

Triple negative (ER, PgR and Her-2/neu negatives) or basal cell carcinomas are a variety of highly proliferative breast neoplasms that could also be identified by the immunohistochemical expression of basal cytokeratins (type 5, 14 or 17) and by DNA microarray studies. ${ }^{50}$ Table 4 summarizes relevant contributions in the characterization of these neoplasms, which are associated with a high histological grade, metaplastic features, wide tumor necrosis, pushing borders and marked lymphoid reaction. ${ }^{19}$ Furthermore, these tumors are related with medullary features ${ }^{32}$ and BRCA1 mutations. ${ }^{18,28}$ Similar clinical and pathological findings were found in the present series.

Rakha et $a l^{17}$ have recently subdivided the basal breast carcinomas into two variants: one, 'pure', 

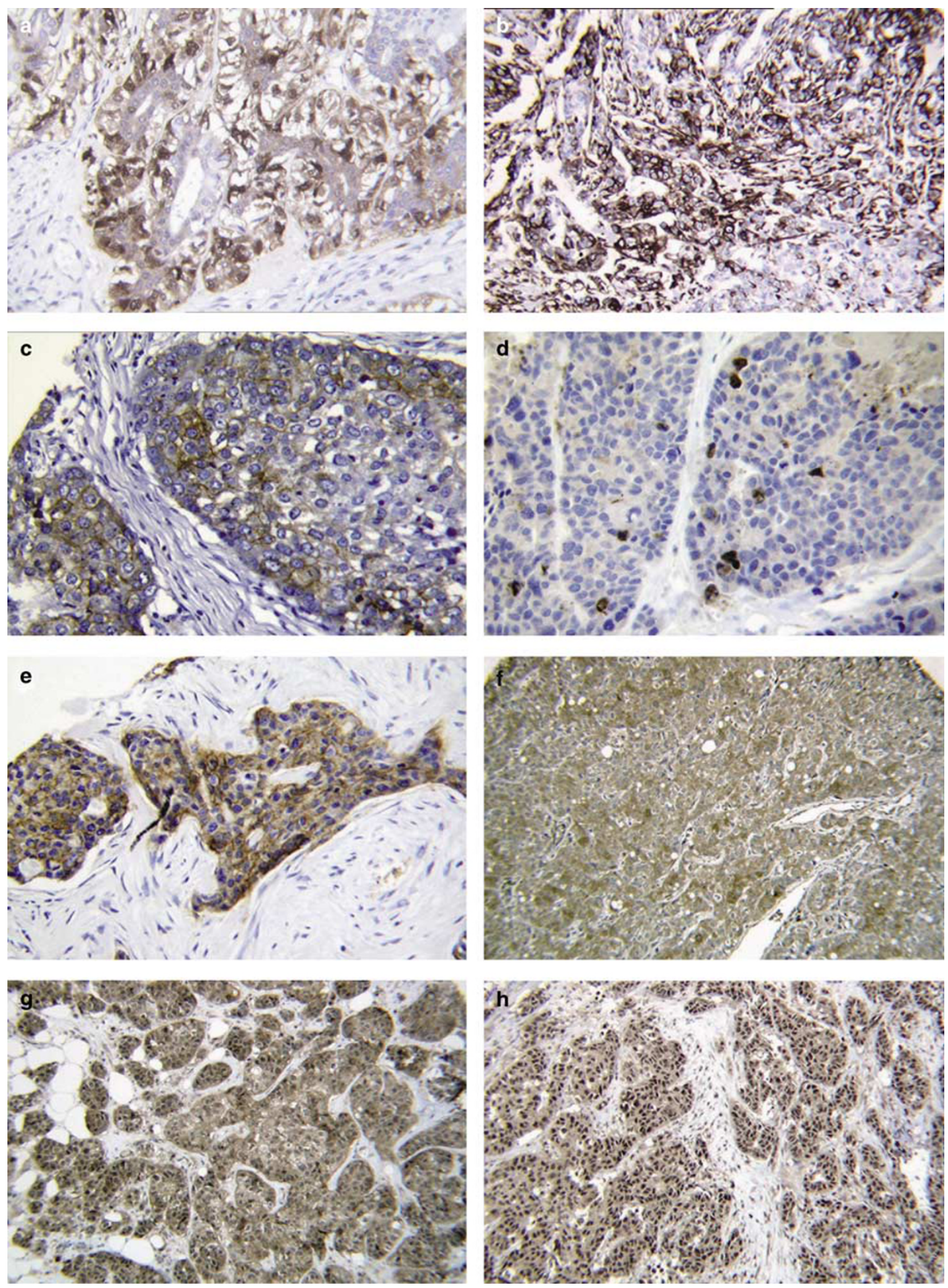

Figure 1 Expression of diverse Ab in basal carcinomas of breast. (a) S-100 $(\times 40)$, (b) vimentin $(\times 20)$, (c) CD117 ( $\times 40)$, (d) caspase-3 $(\times 40)$, (e) EGFR $(\times 20),(\mathbf{f})$ PTEN $(\times 20),($ g $)$ pAkt $(\times 20)$ and $(\mathbf{h})$ p50 $(\times 20)$.

associated with early recurrence and reduced survival, and another with 'myoepithelial' differentiation. Approximately, one-fourth of our series presented myoepithelial differentiation, confirmed by immunohistochemical stains for S-100 and SMA, the former being the more sensitive marker. 
Table 4 Historical contributions for characterization of basal breast carcinomas

Authors

Malzahn et $a l^{25}$

Basal cytokeratin 5, 14 or 17 are associated with agressive breast carcinomas

Perou et $a l^{5}$ Identification of diverse molecular portraits of breast tumors (cDNA)

Tsuda et $a l^{33}$ Myoepithelial tumors (S-100 and cytokeratin 14 positives) have bad prognosis

Sorlie et $a l^{6}$

Tumor gene expression has clinical implications. Basal breast carcinomas are hormone receptors and Her2/neu negatives

van de Rijn et $a l^{22}$

Cytokeratins 17 and 5 related with agressive breast carcinomas

Foulkes et $a l^{18}$

Nielsen et $a l^{21}$ BRCA1 mutations are frequent in basal breast carcinomas

Basal carcinomas are negative for hormone receptors and Her2. Frequent cytokeratin 5, EGFR and CD117 expression

Jones et $a 1^{13} \quad$ Cytogenetic subgroup of grade III, breast carcinomas with cytokeratin 14 expression have poor clinical outcomes

Abd El-Rehim et al ${ }^{15}$ Differences in luminar and basal cytokeratin expressions in breast carcinomas. Frequent EGFR expression

Tsuda et $a l^{34}$ KIT and EGFR are frequent in breast carcinomas with mesenchymal or myoepithelial differentiation

Rakha et $a l^{17}$ Myoepithelial carcinomas may be a subtype of basal breast carcinomas

Bertucci et $a l^{32}$

Medullary features are frequent in basal breast carcinomas

Although most pathological and immunohistochemical results were markedly similar in both subtypes of basal breast carcinomas, we identified several differences: DCIS was more frequent in tumors of the pure variant, whereas necrosis, lymphoid reaction, CD117, activated caspase-3 and vimentin were more common in those with myoepithelial differentiation. Vimentin expression was previously related with some breast carcinomas that today could have been included in the myoepithelial group, ${ }^{33,35}$ whereas the remaining breast carcinomas rarely express vimentin. ${ }^{33}$ Indeed, these tumors can be related to a previously described variety of mammary neoplasms with frequent vascular dissemination, characterized by central acellular areas and expression of cytokeratin 14 and S-100. ${ }^{36}$

The main objective of this study was the exploration of alternative growth metabolic pathways to hormone receptors and Her2/neu in basal breast carcinomas. Rapid growth of these neoplasms could be related with a high Ki67 index and frequent p53 overexpression. The mean Ki67 index of $46 \%$ and the overexpression of p53 in $53 \%$ of our cases is much higher than the mean values described in sporadic and familial breast carcinomas. ${ }^{37}$

Cyclin D1 overexpression has been reported in $60 \%$ of DCIS and $70 \%$ of invasive cancers, ${ }^{37,38}$ in association with a favorable clinical outcome and response to tamoxifen. ${ }^{38}$ In the present series, cyclin D1 overexpression was present in $52 \%$ of tumors in association with loss of p27 nuclear expression, but unrelated to pAkt or ER. In conclusion, cyclin D1 overexpression seems less relevant in the basal subtype than in conventional breast carcinomas.

$\mathrm{NF}-\kappa \mathrm{B}$ has an important role in cell cycle regulation $^{39}$ and may participate in the invasion/metastasis of breast cancer by upregulation of vascular endothelial growth factor mRNA ${ }^{40}$ and matrix metalloproteinases. ${ }^{41}$ Coincident expression of p50 and p65 in $13 \%$ of our tumors suggests the activation of this NF- $\kappa \mathrm{B}$ heterodimer in basal breast carcinomas. The p52-p65 heterodimer was not identified in our series.

Several growth factor receptors were studied in the present series. Epidermal growth factor receptor1 (EGFR or Her-1) and c-erbB-2 (neu or Her-2) expression had been previously detected in 20 and $32 \%$ of breast neoplasms, respectively. ${ }^{15}$ In basal breast carcinoma, overexpression of EGFR is described between 30 and $54 \%,{ }^{15,17,21,24}$ as in this study. EGFR may relate with intracellular signaling kinases, notably mitogen-activated protein kinase and Akt, and promote ER transcriptional activity in a ligand-independent manner, ${ }^{42}$ and this crosslinking could exist in basal breast carcinoma. IGFIR is a member of the type II receptor tyrosine kinase family that regulates cell growth in a variety of neoplasms, including breast cancers. Recently, IGFIR was identified in $\sim 50 \%$ of breast carcinomas, ${ }^{43}$ including ER-negative tumors, ${ }^{44}$ although its presence was unrelated with prognosis or survival. ${ }^{45,46}$ IGF-IR was identified in $36 \%$ of our series and rarely coincided with other growth factor receptors.

CD117 has been detected in $19-31 \%$ of basal breast carcinoma, whereas in conventional breast carcinomas its expression varies from 4 to $14 \% .{ }^{21,24,34}$ In this paper, as in others, ${ }^{34}$ CD117 was mainly present in tumors with myoepithelial differentiation.

Coexpression of EGFR, IGF-IR and CD117 was very rare in our study, and $77 \%$ of all basal breast carcinomas showed at least one of these receptors. Our results suggest that IGF-IR may be relevant in the development of basal breast carcinoma without EGFR.

PTEN is a tumor suppressor gene that inhibits PI3K-dependent activation of Akt. ${ }^{47}$ Lack of PTEN induces Akt phosphorilization (activation), which subsequently promotes cell cycle arrest by decreasing the level and nuclear localization of cyclin $\mathrm{D} 1,{ }^{48,49}$ inactivation of p-Bad, expression of Bcl-2 and inhibition of the Forkhead family of transcription factors. ${ }^{50}$ Lack of PTEN is found in $8-48 \%$ of breast carcinomas and is generally associated with a high grade, necrosis, node metastasis and absence of ER. ${ }^{51-56}$ Generally, PTEN absence in breast carcinomas is due to gene promoter hypermethylation ${ }^{51-55}$ or loss of heterozygosity,$^{53}$ whereas PTEN mutations are exceptional in sporadic neoplasms. ${ }^{57}$ Loss of 
PTEN is rare in basal breast carcinoma, and its relationship with Akt expression could not always be confirmed, ${ }^{51,56}$ as in our series where Akt, present in $28 \%$ of tumors, was more frequently associated with growth factor receptors than with the PTEN pathway. ${ }^{52,57}$ Recently, pAkt overexpression was described in $33 \%$ of in situ and $38 \%$ of ductal invasive breast carcinomas, although without any significant clinicopathological relationship, ${ }^{56}$ as in our cases.

In summary, Ki67 and p53 are higher in basal than in conventional breast carcinomas. The expression of EGFR, IGF-IR and CD117 may have a significant role in basal breast carcinomas, as well the heterodimer p50-p65 (NF- $\kappa$ B) in some cases. PTEN, pAkt, p27 and cyclin D1 alterations occur as in conventional mammary neoplasms. In addition to myoepithelial markers such as S-100 and actin, among others, myoepithelial variant could be differentiated from the pure variant of basal breast carcinomas for more frequent expression of vimentin and CD117.

\section{Acknowledgement}

This work was supported by Grants FISSS PI060709 Ministry of Health, Spain, and Pfizer Grant for Breast Cancer Research (2007). We thank Ms Carolyn Newey for her help with the English text.

\section{Disclosure/conflict of interest}

None.

\section{References}

1 Jemal A, Murray T, Ward E, et al. Cancer statistics, 2005. CA Cancer J Clin 2005;55:10-30.

2 Elledge RM, Fuqua SAW. Estrogen and progesterone receptors. In: Harris $H$ (ed). Diseases of the Breast. Lippincott Williams \& Wilkins: Philadelphia, 2000, p 47.

3 Fitzgibbons FK, Page DL, Weaver D, et al. Prognostic factors in breast cancer: college of American pathologists consensus statement 1999. Arch Pathol Lab Med 2000;124:966-978.

4 Bardou V-J, Arpino G, Elledge RM, et al. Progesterone receptor status significantly improves outcome prediction over estrogen receptor status alone for adjuvant endocrine therapy in two large breast cancer databases. J Clin Oncol 2003;21:1973-1979.

5 Perou CM, Sorlie T, Eisen MB, et al. Molecular portraits of human breast tumours. Nature 2000;406: 747-752.

6 Sorlie T, Perou CM, Tibshirani R, et al. Gene expression patterns of breast carcinomas distinguish tumor subreast carcinomalasses with clinical implications. Proc Natl Acad Sci USA 2001;98:10869-10874.

7 Sorlie T, Tibshirani R, Parker J, et al. Repeated observation of breast tumor subtypes in independent gene expression data sets. Proc Natl Acad Sci USA 2003;100:8418-8423.
8 van't Veer LJ, Dai H, van de Vijver MJ, et al. Gene expression profiling predicts clinical outcome of breast cancer. Nature 2002;415:530-536.

9 Sotiriou C, Neo SY, McShane LM, et al. Breast cancer classification and prognosis based on gene expression profiles from a population based study. Proc Natl Acad Sci USA 2003;100:10393-10398.

10 van de Vijver MJ, He YD, van't Veer LJ, et al. A gene expression signature as a predictor of survival in breast cancer. N Engl J Med 2002;347:1999-2009.

11 Ma XJ, Wang Z, Ryan PD, et al. A two gene expression ratio predicts clinical outcome in breast cancer patients treated with tamoxifen. Cancer Cell 2004;5: 607-616.

12 Huang E, Cheng SH, Dressman H, et al. Gene expression predictors of breast cancer outcomes. Lancet 2003;361:1590-1596.

13 Jones C, Ford E, Gillett C, et al. Molecular cytogenetic identification of subgroups of grade III invasive ductal breast carcinomas with different clinical outcomes. Clin Cancer Res 2004;10:5988-5997.

14 Callagy G, Cattaneo E, Diago Y, et al. Molecular classification of breast carcinomas using tissue microarrays. Diag Mol Pathol 2003;12:27-34.

15 Abd El-Rehim DM, Pinder SE, Paish CE, et al. Expression of luminar and basal cytokeratins in human breast carcinoma. J Pathol 2004;203:661-671.

16 Abd El-Rehim DM, Ball G, Pinder SE, et al. Highthroughput protein expression analysis using microarray technology of a large well characterized series identifies biologically distinct classes of breast cancer confirming recent cDNA expression analyses. Int J Cancer 2005;116:340-350.

17 Rakha EA, Putti TC, Abd El-Rehim DM, et al. Morphological and immunophenotypic analysis of breast carcinomas with basal and myoepithelial differentiation. J Pathol 2006;208:495-506.

18 Foulkes WD, Stefansson IM, Chappuis PO, et al. Germline BRCA1 mutations and basal epithelial phenotype in breast cancer. J Natl Cancer Inst 2003;95: 1482-1485.

19 Livasy CA, Karaca G, Nanda R, et al. Phenotypic evaluation of basal-like subtype of invasive breast carcinoma. Mod Pathol 2006;19:264-271.

20 Gusterson BA, Ross DT, Heath VJ, et al. Basal cytokeratins and their relationship to the cellular origin and functional classification of breast cancer. Breast Cancer Res 2005;7:143-148.

21 Nielsen TO, Hsu FD, Jensen $\mathrm{K}$, et al. Immunohistochemical and clinical characterization of the basal like subtype of invasive breast carcinoma. Clin Cancer Res 2004;10:5367-5374.

22 van de Rijn M, Perou CM, Tibshirani R, et al. Expression of cytokeratins 17 and 5 identifies a group of breast carcinomas with poor clinical outcome. Am J Pathol 2002;161:1991-1996.

23 Rodriguez-Pinilla SM, Sarrio D, Honrado E, et al. Prognostic significance of basal-like phenotype and fascin expression in node-negative invasive breast carcinomas. Clin Cancer Res 2006;12:1533-1539.

24 Kim MJ, Ro JY, Ahn SH, et al. Clinicopathologic significance of basal-like subtype of breast cancer: a comparison with hormone receptor and Her2/neuoverexpressing phenotypes. Hum Pathol 2006;37: 1217-1226.

25 Malzahn K, Mitze M, Thoenes M, et al. Biological and prognostic significance of stratified epithelial cytoker- 
atins in infiltrating ductal breast carcinomas. Virchows Arch 1998;433:119-129.

26 Laakso M, Loman N, Borg A, et al. Cytokeratin 5/14positive breast cancer: true basal phenotype confined to BRCA-1 tumors. Mod Pathol 2005;18:1321-1328.

27 Korsching E, Packeisen J, Agelopoulos K, et al. Cytogenetic alterations and cytokeratin expression patterns in breast cancer: integrating a new model of breast differentiation into cytogenetic pathways of breast carcinogenesis. Lab Invest 2002;82:1525-1533.

28 Haffty BG, Yang Q, Reiss M, et al. Locoregional relapse and distant metastasis in conservative managed triple negative early stage breast cancer. J Clin Oncol 2006;24:5652-5657.

29 Siziopikou KP, Cobleigh M. The basal subtype of breast carcinoma may represent the group of breast tumors that could benefit from EGFR targeted therapies. Breast 2007;16:104-107.

30 Rakha EA, El-Sayed ME, Green AR, et al. Prognostic markers in triple negative breast cancer. Cancer 2007;109:25-32.

31 Elston CW, Ellis IO. Pathological prognostic factors in breast cancer. I. The value of histological grade in breast cancer: experience from a large study with longterm follow-up. Histopathology 1991;19:403-410.

32 Bertucci F, Finetti P, Cervera N, et al. Gene expression profiling shows medullary breast cancer is a subgroup of basal breast cancers. Cancer Res 2006;66:4636-4644.

33 Tsuda H, Takarabe T, Hasegawa F, et al. Large, central acellular zones indicating myoepithelial tumor differentiation in high-grade invasive ductal carcinomas as markers of predisposition to lung and brain metastases. Am J Surg Pathol 2000;24:197-202.

34 Tsuda H, Morita D, Kimura M, et al. Correlation of KIT and EGFR overexpression with ductal breast carcinoma of the solid-tubular subtype, nuclear grade 3 , and mesenchymal or myoepithelial differentiation. Cancer Sci 2005;96:48-53.

35 Hungermann D, Buerger $\mathrm{H}$, Oehlschlegel C, et al. Adenomyoepithelial tumors and myoepithelial carcinomas of the breast-a spectrum of monophasic and biphasic tumours dominated by immature myoepithelial cells. BMC Cancer 2005;5:92 doi:01.1186/14712407-5-92.

36 Korsching E, Packeisen J, Liedtke C, et al. The origin of vimentin expression in invasive breast cancer: epithelial-mesenchymal transition, myoepithelial histogenesis or histogenesis from progenitor cells with bilinear differentiation potential? J Pathol 2005;206:451-457.

37 Palacios J, Honrado E, Osorio A, et al. Phenotypic characterization of BRCA1 and BRCA2 tumors based in a tissue microarray study with 37 immunohistochemical markers. Breast Cancer Res Treat 2005;90: 5-14.

38 Han S, Park K, Bae BN, et al. Cyclin D1 expression and patient outcome after tamoxifen therapy in estrogen receptor positive metastatic breast cancer. Oncol Rep 2003;10:141-144.

39 Chen F, Castranova V, Shi X. New insights into the role of nuclear factor- $\kappa \mathrm{B}$ in cell growth regulation. Am J Pathol 2001;159:387-397.

40 Shibata A, Nagaya T, Imai T, et al. Inhibition of NFkappaB activity decreases the VEGF mRNA expression in MDA-MB-231 breast cancer cells. Breast Cancer Res Treat 2002;73:237-243.

41 Helbig G, Christopherson II KW, Bhat-Nakshatri P, et al. NF-kappaB promotes breast cancer cell migration and metastasis by inducing the expression of the chemokine receptor CXCR4. J Biol Chem 2003;278: 21631-21638.

42 Clark AS, West K, Streicher S, et al. Constitutive and inducible Akt activity promotes resistence to chemotherapy, transtuzumab, or tamoxifen in breast cancer cells. Mol Cancer Ther 2002;1:707-717.

43 Peiró G, Aranda FI, Adrover E, et al. Activated IGF1R in breast cancer with neoadjuvant chemotherapy. Lab Invest 2006;86(Suppl 1):38A.

44 Gee JM, Robertson JF, Gutteridge E, et al. Epidermal growth factor receptor/Her2/insulin-like growth factor receptor signalling and oestrogen receptor activity in clinical breast cancer. Endocr Relat Cancer 2005;12: S99-S111.

45 Kostler WJ, Hudelist G, Rabitsch W, et al. Insulin-like growth factor-1 receptor (IGF-1R) expression does not predict for resistance to trastuzumab-based treatment in patients with Her-2/neu overexpressing metastatic breast cancer. J Cancer Res Clin Oncol 2006;132:9-18.

46 Nahta R, Yuan LX, Zhang B, et al. Insulin-like growth factor-I receptor/human epidermal growth factor receptor 2 heterodimerization contributes to trastuzumab resistance of breast cancer cells. Cancer Res 2005;65:11118-11128.

47 Li J, Yen C, Liaw D, et al. PTEN, a putative protein tyrosine phosphatase gene mutated in human brain, breast and prostate cancer. Science 1997;275: 1943-1947.

48 Chung JH, Eng C. Nuclear-cytoplasmic partitioning of phosphatase and tensin homologue deleted on chromosome 10 (PTEN) differentially regulates the cell cycle and apoptosis. Cancer Res 2005;65:8096-8100.

49 Chung JH, Ostrowski MC, Romigh T, et al. The ERK1/2 pathway modulates nuclear PTEN-mediated cell cycle arrest by cyclin D1 transcriptional regulation. Hum Mol Genet 2006;15:2553-2559.

50 Rhei E, Kang L, Bogomolniy F, et al. Mutation analysis of the putative tumor supressor gene PTEN/MMAC1 in primary breast carcinomas. Cancer Res 1997;57: 3657-3659.

51 Datta K, Franke TF, Chan TO, et al. AH/PH domain mediated interaction between AKT molecules and its potential role in AKT regulation. Mol Cell Biol 1995;15:2304-2310.

52 Panigrahi AR, Pinder SE, Chan SY, et al. The role of PTEN and its signalling pathways, including AKT, in breast cancer; an assessment of relationships with other prognostic factors and with outcome. J Pathol 2004;204:93-100.

53 Depowski PL, Rosenthal SI, Ross JS. Loss of expression of the PTEN gene protein product is associated with poor outcome in breast cancer. Mod Pathol 2001;14:672-676.

54 Perren A, Weng LP, Boag AH, et al. Immunohistochemical evidence of loss of PTEN expression in primary ductal adenocarcinomas of the breast. Am J Pathol 1999;155:1253-1260.

55 Bose S, Crane A, Hibshoosh H, et al. Reduced expression of PTEN correlates with breast cancer progression. Hum Pathol 2002;33:405-409.

56 Garcia JM, Silva J, Peña C, et al. Promoter methylation of PTEN gene is a common molecular change in breast cancer. Genes Chromosomes Cancer 2004;41:117-124.

57 Bose S, Chandran S, Mirocha JM, et al. The Akt pathway in human breast cancer: a tissue-array-based analysis. Mod Pathol 2006;19:238-245. 